\title{
Celiac disease: pathways for diagnosis
}

\section{Doença Celíaca: caminhos para o diagnóstico}

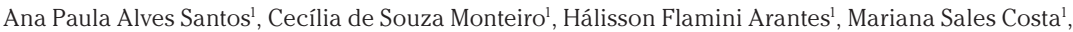 \\ Rodrigo Macedo Rosa ${ }^{2}$, Gustavo Meirelles Ribeiro ${ }^{3}$
}

DOI: $10.5935 / 2238-3182.20140106$

\section{ABSTRACT}

Celiac disease is a chronic autoimmune disease, diagnosed in all age groups, associated with intestinal malabsorption and increasingly frequent extra-intestinal manifestations. Its clinical diagnosis depends on the close clinical, laboratory, and morphological correlation. The clinical suspicion leads to highly sensitive and specific serologic tests; however, the intestinal biopsy remains as a reference test, guided by endoscopy, which reveals villous atrophy in the intestinal mucosa.

Key words: Celiac Disease; Celiac Disease/pathology; Celiac Disease/epidemiology; Celiac Disease/diagnosis; Intestinal Diseases.

\section{RESUMO}

A doença celíaca é uma enfermidade autoimune crônica, diagnosticada em todas as faixas etárias, associada à má-absorção intestinal e com manifestações extraintestinais cada vez mais frequentes. Seu diagnóstico clínico depende da estreita correlação clínica, laboratorial e morfológica. A suspeita clínica conduz a exames sorológicos muito sensíveis e específicos, mas a biópsia intestinal permanece como exame de referência, orientada pela endoscopia, que revela atrofia vilositária da mucosa intestinal.

Palavras-chave: Doença Celíaca; Doença Celíaca/patologia; Doença Celíaca /epidemiologia; Doença Celíaca/diagnóstico; Enteropatias.

\section{INTRODUCTION}

Celiac disease (CD) is an acquired chronic illness, immunologically mediated, with a variety of clinical manifestations. ${ }^{1,2}$ The ingestion of gluten, which is the protein fraction present in wheat, barley, rye, and possibly oats determines lesions on the small intestinal mucosa through autoimmune mechanisms in genetically predisposed individuals. ${ }^{1,3-5}$ The chronic inflammation of the intestinal mucosa with progression to villous atrophy is classically observed. The removal of gluten from the diet provides clinical and histological improvement and its reintroduction leads to recurrence. ${ }^{6,7}$ Their most common characteristic clinical manifestations occur in children and correspond to diarrhea, weight loss, malnutrition, ${ }^{8-10}$ and anemia due to iron deficiency. It can emerge, however, at any age ${ }^{6}$ showing global distribution ${ }^{4}$ among populations, which makes it difficult to determine the group with the highest incidence. The variety of CD clinical presentations contributes to the difficulty in determining the most affected group in a population, especially for the oligo and asymptomatic forms. ${ }^{1}$
${ }^{1}$ Medical School student at the Federal University of Ouro Preto - UFOP. Ouro Preto, MG - Brazil.

${ }^{2} \mathrm{MD}$, Endoscopist. General Hospital of the Federal University of Minas Gerais-UFMG. Belo Horizonte, MG - Brazil. ${ }^{3}$ MD. Assistant Professor of Medicine at the Federal University of Ouro Preto. Ouro Preto, MG - Brazil.
Submitted: 2012/10/10 Approved: 2013/10/15

Institution:

Federal University of Ouro Preto

Ouro Preto, MG - Brazil

Corresponding Author:

Gustavo Meirelles Ribeiro

E-mail: gustavomeirelles@uol.com.br 


\section{EPIDEMIOLOGY}

Recognized in the past as a disease of low prevalence, $\mathrm{CD}$ went on to be diagnosed with increasing frequency worldwide because of the increased availability of highly sensitive and specific serologic tests, ${ }^{1}$ which increased the accuracy of its diagnosis. The expressive increase in the prevalence of $\mathrm{CD}$ over the past few decades has also been observed, ${ }^{11}$ with universal distribution, reaching all ethnicities, and characterized as the most frequent known genetic diseases with an average prevalence in the general population of $1 \%{ }^{9}$ to $2 \% .^{12}$

The index of involvement by $\mathrm{CD}$ in the United States $^{7}$ is approximately 1:100 (1\%) with variations from $1: 80$ to $1: 140$ ( 1.25 to $0.71 \%$ ) with most diagnoses made in later stages of life. ${ }^{13}$ It is known, however, that the occurrence of $\mathrm{CD}$ is underestimated, particularly in developing countries, where its clinical presentation overlaps other frequent diseases such as infectious and malnutrition. ${ }^{1}$ In Brazil, the first study on the prevalence of $\mathrm{CD}$ was performed by Gandolfi et al., ${ }^{14}$ based on serological tests applied to 2,045 blood donors in the city of Brasília. Jejunal biopsy was performed in patients with positive serology, which confirmed three CD cases, i.e. a prevalence of 1:681 (0.15\%).

\section{PATHOGENESIS}

The pathogenesis of $\mathrm{CD}$ involves, although not completely understood, the interaction of genetic, environmental, and immunological factors. ${ }^{9}$

In relation to genetic factors, it appears that it is associated with HLA class II genes - HLA-DQ, ${ }^{2,410,15}$ located on the short arm of chromosome $6 .^{3}$ High prevalence of $\mathrm{CD}$ is recorded among members of the same family and $\mathrm{CD}$ concordance between 70 and $85 \%$ in monozygotic twins. ${ }^{15,16}$ The finding of these genes, however, is necessary but insufficient to the expression of the CD phenotype. ${ }^{15,16}$ Another important aspect to consider is that there are two types of HLA-DQ2 molecules: DQ 2.5 and DQ 2.2, which represent high risk and low risk of $\mathrm{CD}$, respectively, and present in about $95 \%$ of CD patients whereas the HLA-DQ8 allelic variant correspond to other cases. ${ }^{3}$ HLA molecules synthesized from these genes are present on antigen-presenting cells, macrophages, dendritic cells, and LB found in the proximal small intestine mucosa. ${ }^{4}$ In the immunological point of view, CD patients display disturbances in the regula- tion of LT CD4 + response in part of the population of HLA-DQ2 or HLA-DQ8 carriers. ${ }^{410}$

$\mathrm{CD}$ is an inflammatory disease triggered by the exposure to wheat gluten, compound formed by albumins, globulins, gliadins, and glutenins. Gliadins and glutenins are rich in glutamines, a peptide capable of triggering an inflammatory reaction in the intestinal mucosa. Other proteins, called prolamins, contain glutamines and are found in barley (hordeins), rye (secalins), and possibly in oats (avenins)..$^{16}$ The enzyme tissue transglutaminase (tTG), which occurs in various cells of the body, including enterocytes, ${ }^{2}$ uses glutamine as its substrate. The tTG acts deaminizing glutamine residues that bind to HLADQ2/DQ8 molecules, present in dendritic cells of susceptible individuals, and activate gluten-specific LT CD4 + cells..$^{15}$ LT CD4 + cells produce cytokines, which in turn activate the Th1 type inflammatory response. The Th1 inflammatory reaction leads to villus atrophy and hyperplasia of crypts $^{2,16}$ through the degradation of extracellular matrix proteins and the basal membrane of the intestinal mucosa by the production of metalloproteinases, enhancing cytotoxicity of intraepithelial lymphocytes or LT NK (natural killer), promoting apoptosis of enterocytes. The concomitant activation of LBs that differentiate into plasma cells and produce antibodies anti-tTG and anti-gliadin is still observed..$^{15}$

Other factors also relate to the development of $\mathrm{CD}$ such as exposure to gluten before three months of age, gastrointestinal infections before six months of age, especially those caused by rotavirus, ${ }^{10}$ and alterations in the intestinal microbiota. ${ }^{2}$

\section{CLINICAL PRESENTATION}

Until the early 80 s, the symptoms described in $\mathrm{CD}$ were only located in the digestive system, mainly characterized by intestinal malabsorption. From that time onwards, thanks to the use of serology techniques, the number of patients with less severe symptoms became twice greater than patients with malabsorption. ${ }^{15}$ It is estimated that over $80 \%$ of patients with positive serology are asymptomatic or only mildly symptomatic, presenting only extra-intestinal symptoms. ${ }^{2}$ Thus, the diagnosis of CD tends to be difficult, with discordance between clinical signs and symptoms, and serology and intestinal biopsy in about 10\% of cases. ${ }^{9}$ Among children, chronic diarrhea, abdominal distention, vomiting, and constipation are classic 
manifestations. ${ }^{5,6}$ Reduced growth, loss of appetite, anemia (mainly iron deficiency), and depression are also observed. CD can also be associated with herpetiformis dermatitis, tooth enamel defects, diabetes mellitus type I, IgA deficiency, Down syndrome, Turner syndrome, and positive history of CD in first-degree relatives. In chronic diarrhea and $\mathrm{CD}$, the lack of iron, folate, calcium, and fat-soluble vitamins, caused by intestinal malabsorption, must be investigated. ${ }^{6}$

The main extra-intestinal manifestations in CD, often not associated with gastrointestinal symptoms, are: herpetiformis dermatitis, iron deficiency, osteoporosis, recurrent miscarriage, infertility, ataxia, peripheral neuropathy, and dyspepsia. ${ }^{17}$ Its association with several autoimmune diseases (mainly type I diabetes mellitus, hypo-or hyperthyroidism, Sjögren's syndrome), prolonged fatigue, ataxia, persistent elevation of serum transaminases, and malignant neoplasms, especially lymphoma and adenocarcinoma of the small intestine are also reported. ${ }^{6,9,18}$

The presentation of $\mathrm{CD}$ is divided into five phenotypes or forms: ${ }^{7}$

- classic: characterized by gastrointestinal symptoms associated with intestinal malabsorption that evolves with intestinal villus atrophy and other histological alterations related to the ingestion of gluten. The diagnosis of these patients is based on gastrointestinal symptoms;

- atypical: the most frequent presentation, defined by the occurrence of few or no gastrointestinal symptoms. Extra-intestinal manifestations such as iron deficiency anemia, osteoporosis, short stature, and infertility are present and generally motivate the search for medical assistance. Despite evolving with intestinal villus atrophy associated with gluten, these patients often remain undiagnosed because of their vague specific symptoms;

- silent: identified in asymptomatic patients with gluten-induced villus intestinal atrophy. The diagnosis usually depends on positive serology or esophagogastroduodenoscopy, with intestinal biopsies indicated for various reasons. It is asymptomatic with regard to gastrointestinal and extraintestinal symptoms;

- latent: characterized in patients with previous diagnosis of CD who responded satisfactorily to the gluten free diet and remain asymptomatic with normal histology or only increased number of intraepithelial lymphocytes (LIE) after the reintroduction of gluten in the diet. Asymptomatic patients with normal histology in the small intestine are also included in this group, who subsequently will develop CD;

- refractory: represented by the group of patients with a sure diagnosis of $\mathrm{CD}$ who have not responded adequately to the gluten-free diet or, after initial period of good clinical response, presented reappearing symptoms, despite the maintenance of a gluten-free diet for at least 6 to 12 months after malignancy exclusion. Complications associated with CD, such as ulcerative jejunitis and LT lymphoma associated with gluten-induced enteropathy, must be considered in these cases.

\section{DIAGNOSIS}

The CD diagnosis is based on clinical manifestations, laboratory examinations, use of highly sensitive and specific serologic markers, particularly in highrisk populations, and histological aspects of small intestine biopsies.

\section{Serology}

The investigation of serological markers in $\mathrm{CD}$ is a valuable tool to select candidates for intestinal biopsies, a procedure that is essential for a diagnosis of certainty. ${ }^{1,5,6,9,18,19}$ The following presents some points about the use of serological tests.

The amount of ingested gluten as well as the use of immunosuppressive drugs alters the production of antibodies. In asymptomatic children belonging to risk groups, the research for antibodies should be made after three or four years of age, with intake of gluten-containing diet for at least one year. ${ }^{1}$ Antibody titers fall with the gluten free diet between three and 12 months, ${ }^{6,9}$ however, this can be extended up to 31 months when titers were very high before treatment. ${ }^{6}$

Seroconversion precedes villus alterations, therefore, a patient can present high titers of antibodies and absence of alterations when submitted to the biopsy. ${ }^{6}$ The sensitivity of serological tests, however, is proportional to the degree of villus atrophy, and when histological alterations are discreet, the research for antibodies can result as negative, which does not mean absence of disease. ${ }^{9}$ Thus, the intestinal biopsy in symptomatic patients with negative serology becomes justifiable..$^{18}$ The presence of positive serology with biopsy without evidence of significant morpho- 
logical alterations may indicate false positive results, oligosymptomatic disease, or the latent form of CD.,19

The antibodies researched are in the immunoglobulin A class ( $\operatorname{Ig} \mathrm{A})$, however, higher incidence of primary IgA deficiency in $\mathrm{CD}$ is observed; ${ }^{1,5,6,18}$ the most frequent among all primary immune deficiencies. This immunodeficiency has variable prevalence within ethnic profiles in each population and is associated with various autoimmune diseases, including CD. It is therefore, advisable to quantitate serum IgA and CD specific antibodies in symptomatic patients. In cases of primary IgA deficiency, antibodies in the immunoglobulin G class (IgG) must be researched. ${ }^{5}$ The characteristic CD symptomatology in patients with IgA deficiency and positive IgG class antibodies requires intestinal biopsy. ${ }^{6}$

The most sensitive and specific antibodies are tissue anti-transglutaminases (antitTG) and anti-endomysium (EMA), both in the IgA class, ${ }^{5,6,9,18}$ anti-tTG is universally recommended in the investigation of CD. ${ }^{1,18,19}$ It is estimated that around $30 \%$ of CD patients show discrepancies between positivity to anti-tTG and anti-EMA; in these patients, the simultaneous research for both antibodies, whenever possible, is useful. ${ }^{6}$

Anti-tTG is an antibody against the transglutaminase enzyme, responsible for the deamination of gliadin. The anti-tTG IgA test is performed by the ELISA method, with first and second generation techniques, showing sensitivity and specificity of 90 and $95.3 \%$, and 95.3 and $98.3 \%$, respectively. False-positive results associated with chronic liver disease, heart failure, arthritis, diabetes mellitus, food allergies, giardiasis, autoimmune disease, esophagitis, gastritis, cystic fibrosis, and inflammatory bowel disease can occur. ${ }^{5,9,19}$

The anti-EMA IgA research has sensitivity between 86 and 100\% and specificity between 90 and $100 \% .{ }^{15}$ It can be performed concurrently with the research for anti-tTG IgA and enables the clearance of false-negative cases for anti-tTG IgA. ${ }^{18}$ It is detected by indirect immunofluorescence and laboratory operator dependent; it demands more time to perform compared to ELISA. ${ }^{9}$

The research for anti-gliadin antibodies (AGA IgA) is performed by the ELISA method, with specificity around $90 \%$ and sensitivity around $85-90 \% .{ }^{9}$ Due to its low accuracy, its investigation is not indicated for $\mathrm{CD}$, except in children under two years of age. ${ }^{19}$

The serological tests for $\mathrm{CD}$ investigation should be performed or suggested in an extensive range of clinical situations (Tables 1 and 2). ${ }^{20}$
Table 1 - Set of signs, symptoms, and conditions that isolated or not, indicate serologic testing for $\mathrm{CD}$ in children and adults

\begin{tabular}{|c|c|}
\hline Signs and symptoms & Conditions \\
\hline Chronic or intermittent diarrhea & Autoimmune thyroid disease \\
\hline Delay in development (children) & Herpetiformis dermatitis \\
\hline $\begin{array}{l}\text { Persistent and unexplained gas- } \\
\text { trointestinal symptoms Including } \\
\text { nausea and vomiting }\end{array}$ & $\begin{array}{c}\text { First-degree relatives of patients } \\
\text { with CD (parents, siblings, and } \\
\text { children) }\end{array}$ \\
\hline Persistent fatigue & Diabetes mellitus type 1 \\
\hline $\begin{array}{l}\text { Persistent abdominal pain, } \\
\text { bloating, cramps }\end{array}$ & Irritable bowel syndrome \\
\hline \multicolumn{2}{|l|}{ Sudden and unexplained weight loss } \\
\hline $\begin{array}{l}\text { Unexplained iron deficiency ane- } \\
\text { mia or nonspecific anemia }\end{array}$ & \\
\hline
\end{tabular}

Table 2 - Set of conditions that isolated or not, indicate serological testing for $\mathrm{CD}$ in children and adults

\begin{tabular}{l|c}
\hline \multicolumn{1}{c}{ Signs and symptoms } & \multicolumn{1}{c}{$\begin{array}{c}\text { Conditions } \\
\text { Addison's disease }\end{array}$} \\
\hline Amenorrhea & $\begin{array}{c}\text { Microscopic colitis } \\
\text { constipation }\end{array}$ \\
\hline $\begin{array}{l}\text { Bone metabolism diseases } \\
\text { (rickets or osteomalacia) }\end{array}$ & $\begin{array}{c}\text { Persistent elevation of liver } \\
\text { enzymes of unknown cause }\end{array}$ \\
\hline Autoimmune liver diseases & Polyneuropathy \\
\hline Autoimmune myocarditis & Recurrent abortion \\
\hline Chronic thrombocytopenic purpura & Reduced bone mineral density \\
\hline Dental enamel defects & Sarcoidosis \\
\hline Depression or bipolar disorder & Sjogren's syndrome \\
\hline Down syndrome & Turner syndrome \\
\hline Epilepsy & Unexplained alopecia \\
\hline Bone fractures by mild trauma & Unexplained Subfertility \\
\hline Lymphoma & Aphthous stomatitis (mouth ulcers) \\
\hline Adapted from: National Institute for Clinical Excellence (NICE) guidelines. ${ }^{20}$
\end{tabular}

\section{HLA typing}

The occurrence of HLA DQ2/DQ8 genes is of great importance for the $\mathrm{CD}$ diagnosis. It is observed in more than 98\% of people affected by CD. ${ }^{3}$ The isolated detection of these genes, however, does not allow a precise diagnosis because their occurrence is frequent in the general population. ${ }^{15}$ Is is recommended for families of patients with $\mathrm{CD}$ and symptomatic individuals with positive serology who refuse to have an intestinal biopsy performed. ${ }^{9}$

\section{Digestive endoscopy}

The digestive endoscopy enables the direct and detailed study of the intestinal mucosa through the 
acquisition of duodenal biopsies. Some endoscopic aspects are described as associated with intestinal villus atrophy, the phenotypic characteristic most meaningful in $\mathrm{CD}$. These aspects, recognized as endoscopic CD markers, singly or in association, reinforce the indication of duodenal biopsy and assist in targeting the specific sites to be biopsied. These macroscopic alterations are relevant because the intestinal involvement can be sparse, with areas of normal mucosa interspersed with affected areas (patchy villous atrophy). In asymptomatic individuals, the diagnostic opportunity may depend on the endoscopic aspects, with the indication of duodenal biopsies considering endoscopic markers for villus atrophy. ${ }^{21,22}$

There is ample description of endoscopic aspects potentially related to intestinal villus atrophy such as:

- reduction or absence of duodenal folds;

- staggered folds, i.e, nodular appearance of duodenal folds (scalloping of folds);

- strong evidence of a submucosa vascular pattern;

- mosaic pattern, i.e. micro-nodular appearance (cobblestone) in the surface mucosa;

- cracks, grooves, or mucous slots (Figure 1). ${ }^{21}$

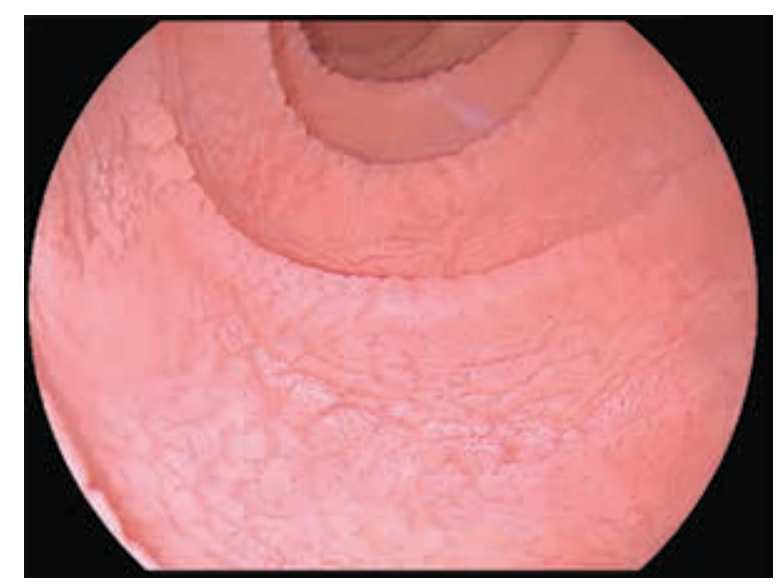

Figure 1 - Aspect of the endoscopic of the second duodenal portion using the immersion technique. Reduction in mucosa staggered folds and cracks (scalloping of folds). Photo obtained from the personal archive of the author (Rosa, RM).

The sensitivity and specificity rates of endoscopic markers for the diagnosis of CD vary between 66 and $94 \%$ and 83 and $100 \%$, respectively. ${ }^{21}$

The recognition of any alteration in the mucosa potentially related to villus atrophy should be considered by the endoscopist as unquestionable indication for duodenal biopsies. The low sensitivity of endoscopic markers means, however, that their absence do not ex- clude the diagnosis of CD; biopsies should always be performed in suspicious cases. ${ }^{21}$

\section{Intestinal biopsy}

The isolated histological analysis, although not enough for the diagnosis of CD plays a major role. ${ }^{9}$ The collection of intestinal biopsies, a fundamental procedure for the diagnosis of $\mathrm{CD}$, requires some care about the number of fragments, site, preparation of the material for analysis, and histological interpretation. Multiple biopsies must be performed, preferably between four and six, with at least one from the duodenal bulb. The bulbar biopsy is justified by the possibility of uneven and intercalated involvement of the mucosa, sometimes with the mucosal histological alterations being restricted to this topography. Biopsies obtained in conjunction with the second and/or third parts of the duodenum have the potential to confirm, in practice, the histological diagnosis in all cases of $\mathrm{CD} .{ }^{23}$

The histological analysis of fragments must be performed by a trained pathologist and based on the following parameters: increase in LIE and architecture of villi and crypts using the criteria established by MarshOberhuber ${ }^{24}$ and later by Corazza. ${ }^{25}$

The classification of Marsh-Oberhuber ${ }^{24}$ groups lesions into five types: 0 : normal mucosa; 1 : only an increase in the number of LIE; 2: increase in the number of LIE and hyperplasia of crypts; 3 : division into three subtypes: $3 \mathrm{a}$ : increase in the number of LIE, hypertrophy of crypts, and slight villus hypotrophy; $3 \mathrm{~b}$ : increase in the number of LIE, hypertrophy of crypts, and accentuated villus hypotrophy; 3c: increase in the number of LIE, hypertrophy of crypts, and total villus atrophy; 4: atrophic mucosa without LIE increase and without hypertrophy of crypts.

The classification of Corazza ${ }^{25}$ simplifies the previous classification and groups types 1 and 2 from MarshOberhuber in group A, types 3a and 3b in group B1, and type $3 \mathrm{c}$ in group B2; type 4 is disregarded in this classification (Table 3).

The increase in LIE considered in isolation can be found in patients with autoimmune diseases, in users of steroids and non-steroidal anti-inflammatory drugs, and in patients with latent CD. ${ }^{9}$ The sampling of the duodenal bulb, although it may be affected by the action of gastric hydrochloric acid, can show early lesions for being the site where gluten has the first contact with the intestinal mucosa. ${ }^{18}$ The symptoms generally correlate with morphological alterations, therefore, 
asymptomatic or oligosymptomatic patients can present discrete mucosa alterations. Patients under gluten free diet must wait at least four weeks with ingestion of gluten diet prior to biopsy. It may happen, however, in some cases, that the intestinal mucosa alterations take years to emerge. ${ }^{9}$

Table 3 - Histological diagnosis of celiac disease. Correspondence between the Marsh-Oberhuber and Corazza and Villanacci classifications

\begin{tabular}{c|c}
\hline Marsh-Oberhuber & Corazza and Villanacci \\
\hline Type 1 & Grade A \\
Type 2 & \\
Type 3 a & Grade B1 \\
Type 3 b & Grade B2 \\
Type 3 c & Excluded \\
\hline Type 4 & \\
\hline
\end{tabular}

Adapted from: Corazza GR, Villanacci ${ }^{25}$.

Despite that the performance of intestinal biopsy is an essential component in the diagnosis of $\mathrm{CD}$, its interpretation must occur in close communication between the clinician and pathologist. The histological analysis should offer full and easy description. The pathologist must recommend, if necessary, serological tests and new follow-up biopsies, or consult the opinion of another professional with special training in gastrointestinal pathology. These recommendations were designed to achieve standardization and allow agreement between pathologists, clinicians, and researchers.

\section{TREATMENT}

The treatment of $\mathrm{CD}$ is the definitive and complete restriction of gluten in the diet (a gluten-free diet). Some patients, however, present the refractory form of the disease and new therapies have been developed for these cases. Some adopted alternatives, with more or less success, include: the use of genetically modified flours with reduction in immunogenic epitopes; b) prior degradation of gliadin peptides, which resist the intestinal proteases by exogenous endopeptidases; c) ingestion of neutralizing antibodies ( $(\mathrm{gG}){ }^{2}$

\section{CONCLUSIONS}

This study shows the importance of identifying groups of patients with increased risk of $\mathrm{CD}$, focusing on early and precise diagnosis, because the majority of patients affected by this condition do not present symptoms or present imprecise symptoms with confusing descriptions of complaints. Patients with autoimmune disorders, particularly diabetes mellitus type I, anemia, hepatic alterations, osteopenia/osteoporosis, and others cited previously require more clinical attention since they can be affected by $\mathrm{CD}$. Another relevant issue is that, contrary to what occurred in the past when the higher prevalence of $\mathrm{CD}$ was in children, its incidence in its multiple forms of manifestation grows among adults and elders. Finally, no isolated exam, not even the intestinal biopsy, is enough to ensure an accurate diagnosis of $\mathrm{CD}$, which requires a close correlation between clinical, laboratory, endoscopic, and histological findings for an improved identification and treatment of $\mathrm{CD}$.

\section{ACKNOWLEDGEMENTS}

The authors are thankful for Mariza Andrade Macedo Rosa for the linguistic and technical revision of the manuscript.

\section{REFERENCES}

1. Fasano A, Araya M, Bhatnagar S, Cameron D, Catassi C, Dirks M, et al.Federation of International Societies of Pediatric Gastroenterology, Hepatology, and Nutrition Consensus Report on Celiac Disease. J Pediat Gastr Nut. 2008; 47(2):214-9.

2. Schuppan D, JunkerY,Barisani D. Celiac disease: from pathogenesis to novel therapies. Gastroenterology.2009; 137(6):1912-33.

3. Kneepkens CMF, von Blomberg BME. Clinical Pratice. Coeliac disease. Eur J Pediatr. 2012; 171:1011-21.

4. Silva TSG. Prevalência de anormalidades relacionadas à tireóide em adultos com doença celíaca [Dissertação]. Porto Alegre: Universidade Federal do Rio Grande do Sul; 2010.

5. Hill ID, Dirks MH, Liptak GS, Colletti RB, Fasano A, Guandalini S, et al. Guideline for the Diagnosis and Treatment of Celiac Disease in Children: Recommendations of the North American Society for Pediatric Gastroenterology, Hepatology and Nutrition. J Ped Gastr Nut. 2005; 40(1):1-19.

6. Green PHR,Jabri B.Coeliac disease.Lancet.2003;362(9381):383-91.

7. Rostom A, Murray JA, Kagnoff MFAmerican Gastroenterological Association (AGA) Institute Technical Review on the Diagnosis and Management of Celiac Disease. Gastroenterology. 2006; 131(6):1981-2002.

8. Tajuddin T, Razif S, Thorne J, Murray FE. Clinical presentation of adult coeliac disease.Irish Med J.2009; 104(1):20-2.

9. Silva TSG, Furlanetto TW. Diagnóstco de doença celíaca em adultos. Rev Assoc Med Bras. 2010; 56(1):122-6. 
10. Barton SH, Murray JA. Celiac disease and autoimmunity in the gut and elsewhere. Gastroenterol. Clin N.2008;37(2):411-28.

11. Rubio-Tapia A, Kyle RA, Kaplan EL, Johnson DR, Page W, Erdtmann F, et al. Increased Prevalence and Mortality in Undiagnosed Celiac Disease. Gastroenterology. 2009; 137(1):88-93.

12. Walker MM, Murray JA, Ronkainen J,Aro P,Storskrubb T, D'Amato $\mathrm{M}$, et al.Detection of Celiac Disease and Lymphocytic Enteropathy by Parallel Serology and Histopathology in a PopulationBased Study. Gastroenterology. 2010; 139(1):112-9.

13. Kagnoff MF AGA Institute Medical Position Statement on the Diagnosis and Management of Celiac Disease.Gastroenterology. 2006; 131(6):1977-80.

14. Gandolfi L, Pratesi R, Cordoba JCM,Tauil PL, Gasparin M, Catassi C. Prevalence of celiac disease among blood donors in Brazil. Am J Gastroenterol.2000; 95(3):689-92.

15. Di Sabatino A, Corazza GR. Coeliac disease. Lancet. 2009; 373(9673):1480-93.

16. Kagnoff MFCeliac disease: pathogenesis of a model immunogenetic disease.J Clin Invest. 2007; 117(1):41-9.

17. Fasano A, Catassi C. Current approaches to diagnosis and treatment of celiac disease: an evolving spectrum. Gastroenterology. 2001; 120(3):636-51.
18. Walker MM, Murray JA. An update in the diagnosis of coeliac disease. Histopathology. 2011; 59(2):166-79.

19. Volta U,Villanacci V. Celiac disease: diagnostic criteria in progress. Cell Mol Immunol.2011;8(2):96-102.

20. National Institute for Clinical Excellence (NICE) guidelines - Coeliac disease: Recognition and assessment of coeliac disease. [Cited 2009 Nov 20]. Available from: http://www.nice.org.uk/ nicemedia/live/12166/44356/44356.pdf.

21. Cammarota G, Fedeli P, Gasbarrini A. Emerging technologies in upper gastrointestinal endoscopy and celiac disease. Nat Clin Pract Gastr. 2009; 6(1):47-56.

22. Brocchi E, Tomassetti P, Misitano B, Epifanio G, Corinaldesi R, Bonvicini F, et al. Endoscopic markers in adult coeliac disease. Digest Liv Dis. 2002; 34(3):177-82.

23. Rashid M, MacDonald A. Importance of duodenal bulb biopsies in children for diagnosis of celiac disease in clinical practice. BMC Gastroenterol.2009; 9(1):1-7.

24. Oberhuber G, Granditsch G,Vogelsang H.The histopathology of coeliac disease: time for a standardized report scheme for pathologists. Eur J Gastroen Hepatol. 1999; 11(10):1185-6.

25. Corazza GR, Villanacci V. Coeliac disease. Some considerations on the histogical diagnosis.J Clin Pathol.2005; 58(6):573-4. 